\title{
Yellow Nail Syndrome:
}

\section{Report of Two Cases and a Brief Review of the Current Literature}

\author{
Eunice Oliveira, Sofia Marques Santos, Nuno Ferreira Monteiro, Maria Manuela Soares, Alberto Mello e Silva \\ Department of Internal Medicine, Egas Moniz Hospital, Lisbon, Portugal
}

Received: 01/11/2015

Accepted: $12 / 12 / 2015$

Published: 29/12/2015

\begin{abstract}
How to cite this article: Oliveira E, Marques Santos S, Ferreira Monteiro N, Soares MM, Mello e Silva A. Yellow nail syndrome: report of two cases and a brief review of the current literature. EJCRIM 2015;2:doi:10.12890/2015_000333
\end{abstract}

Conflicts of Interests: The authors declare that there are no competing interests.

This article is licensed under a Commons Attribution Non-Commercial 4.0 License

\section{ABSTRACT}

Yellow Nail Syndrome (YNS) is a rare, and probably misdiagnosed, condition. It must be considered in middle-aged patients with unexplained chronic respiratory manifestations, lymphedema and nail abnormalities.

We present two cases of undiagnosed YNS until the current admissions, despite several years of investigation. The authors wish to draw attention to this syndrome, of which diagnosis is clinical and of exclusion.

\section{LEARNING POINTS}

- Yellow nail syndrome is characterized by abnormal nails, lymphedema and respiratory manifestation.

- Diagnosis is clinical and should raise the suspicion of underlying medical conditions. The treatment is symptomatic.

\section{KEYWORDS}

Yellow nail; respiratory symptoms; lymphedema.

\section{INTRODUCTION}

Yellow Nail Syndrome (YNS) is an unusual disorder first described in $1964^{1}$ and 30 case reports have been published on this condition in the last 5 years. It presents usually between the forty and sixty decades of life ${ }^{1}$ and is characterized by dystrophic yellow nails, lymphedema and chronic respiratory manifestations (respiratory tract infections, pleural effusions, bronchiectasis, chronic cough, and rhinosinusitis) ${ }^{2}$. The presence of two of these clinical components is sufficient to make a diagnosis of $\mathrm{YNS}^{3}$. An association with pericardial effusion is also described in a few case reports ${ }^{2}$. The cause of YNS remains unclear but an association has been described with systemic diseases, malignancies, immunodeficiency states or even drugs, and may be the reason why this diagnosis should prompt further investigations for related conditions ${ }^{1}$.

\section{CASE REPORT 1}

A 67-year-old woman, hospitalized with Acute Bronchitis, revealed that she was healthy until 5 years prior, when her respiratory complaints had started (bronchiectasis complicated by recurrent respiratory tract infections). There was no history of smoking, allergies, or occupational exposure. She had an episode of pleural effusion not clarified 4 years prior and, at the same time, she noted a discolouration, slow growth and thickening of her nails. Her medical history also included right breast cancer and treatment for hypothyroidism.

Physical examination revealed a respiratory rate of $18 / \mathrm{min}$, with $90 \%$ oximetry room air; vesicular murmur diminished with bilateral crackles; finger and toenails were yellow, thick, dystrophic and over-curved (Fig. 1 and 2); lymphedema of lower limbs. Remaining examination was 


\begin{tabular}{|c|c|c|}
\hline Haematology/ Biochemistry/ Imunology & Reference range & Case Report 1 \\
\hline Haemoglobin (g/dl) & $12.0-15.0$ & 12.4 \\
\hline White blood cells (/mm3) & $4.000-10.000$ & 14.700 \\
\hline Neutrophils (\%) & $40-80$ & 82.1 \\
\hline Platelet count (/mm3) & $150.000-400.000$ & 281.000 \\
\hline C-reactive protein (mg/dl) & $<0.5$ & 13.2 \\
\hline Erythrocyte sedimentation rate $(\mathrm{mm} / \mathrm{h})$ & $<20$ & 99 \\
\hline Creatinine (mg/dl) & $0.52-1.04$ & 0.57 \\
\hline Urea (mg/dl) & $15-36$ & 38 \\
\hline Total proteins (g/dl) & 6.2-.8.6 & 6.3 \\
\hline Albumin (g/dl) & $3.5-5.0$ & 3.5 \\
\hline Protein electrophoresis & & $\begin{array}{l}\text { inflammatory / } \\
\text { infeccious stage }\end{array}$ \\
\hline BNP threshold (pg/ml) & $<125$ & 124 \\
\hline Sodium (mmol/l) & $136-145$ & 135 \\
\hline Potassium (mmol/l) & $3.50-5.10$ & 4.10 \\
\hline Aspartate aminotransferase (U/L) & $14-36$ & 16 \\
\hline Alanine aminotransferase (U/L) & $10-52$ & 24 \\
\hline Alkaline phosphatase (U/L) & $25-100$ & 98 \\
\hline Lactate dehydrogenase (U/L) & $313-618$ & 376 \\
\hline $\mathrm{TSH}(\mu \mathrm{U} / \mathrm{ml})$ & $0.46-4.68$ & 1.63 \\
\hline Free T4 (pmol/l) & $10.9-28.2$ & 19.5 \\
\hline Antinuclear antibodies* & negative & Negative \\
\hline Rheumatoid factor (UI/ml) & $<15$ & $<9.2$ \\
\hline Antineutrophil cytoplasmic antibodies ${ }^{* *}$ & negative & Negative \\
\hline C3 complement/ C4 complement (mg/dl) & $90-180 / 10-40$ & $120 / 31$ \\
\hline Hepatitis B surface antigen (HBsAg) & negative & Negative \\
\hline Anti-hepatitis C virus (anti-HVC) & negative & Negative \\
\hline Anti-HIV 1 and 2 antibodies & negative & Negative \\
\hline \multicolumn{3}{|l|}{ Urine } \\
\hline Erytrocyte & negative & Negative \\
\hline Leukocyte & negative & Negative \\
\hline Protein & negative & Negative \\
\hline
\end{tabular}

Table 1: Patient's laboratory tests

*inclues anti-Ro antibodies, anti-La antibodies, anti-SM antibodies, anti-nRNP antibodies, anti-Scl-70 antibodies, anti-Jo1 antibodies;

*** perinuclear and cytoplasmic

normal. The chest $\mathrm{x}$-ray showed diffuse fibrotic pattern and high-resolution computed tomography (CT) of the chest revealed bilateral bronchiectasis (Fig. 3). The patient's laboratory tests are presented on Table 1.

Blood and sputum cultures were negative, including acid-fast bacillus. A previous diagnosis of YNS was assumed and the patient was treated with antibiotic, diuretics and respiratory therapy with improvement of symptoms and without further hospital admissions. Six months later, the patient was diagnosed with left breast cancer and she was submitted to a total left mastectomy. 


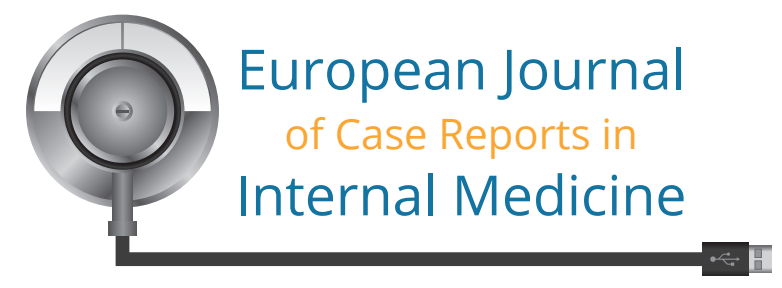

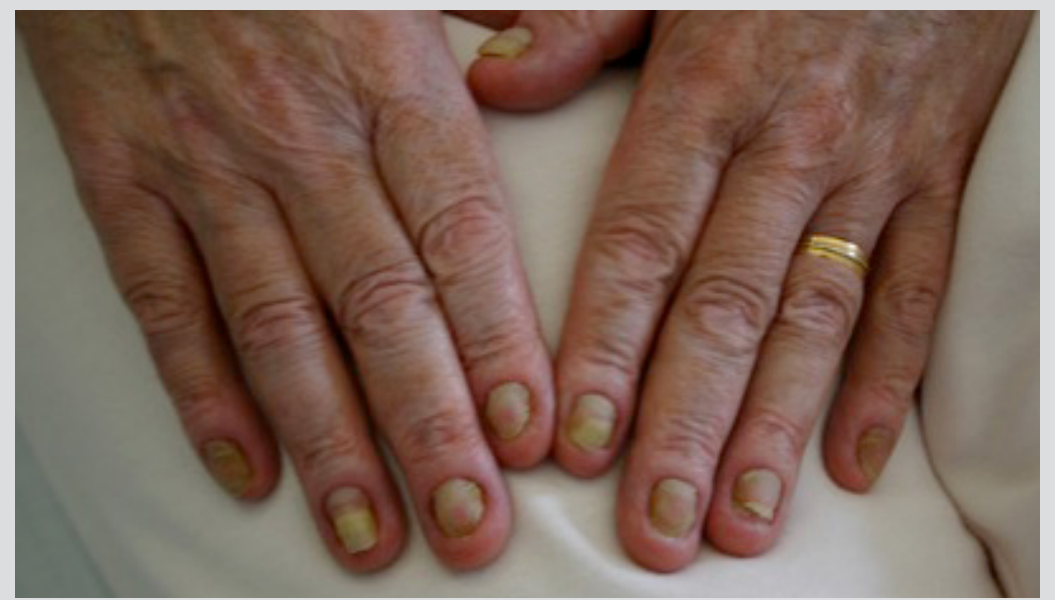

Figure 1: The fingernails

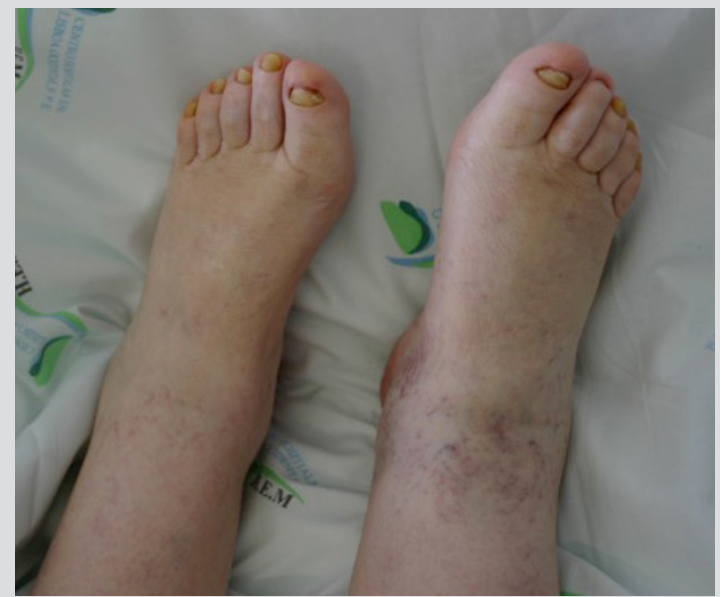

Figure 2: The toenails

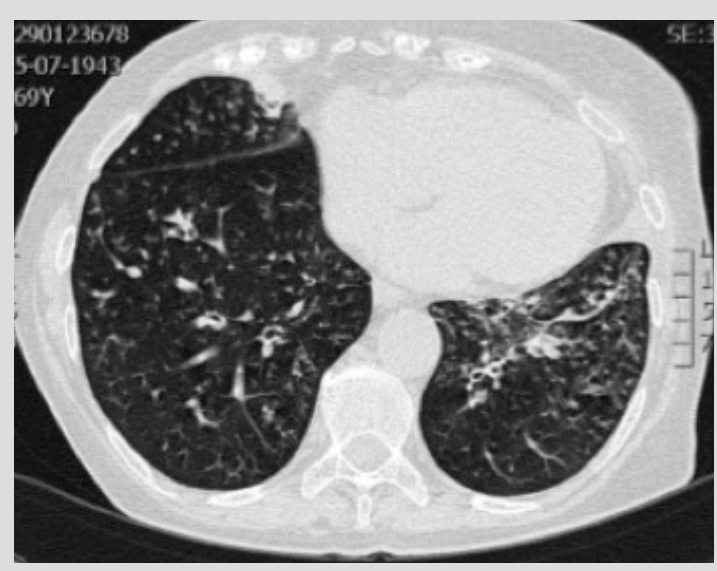

Figure 3: Bilateral bronchiectasis

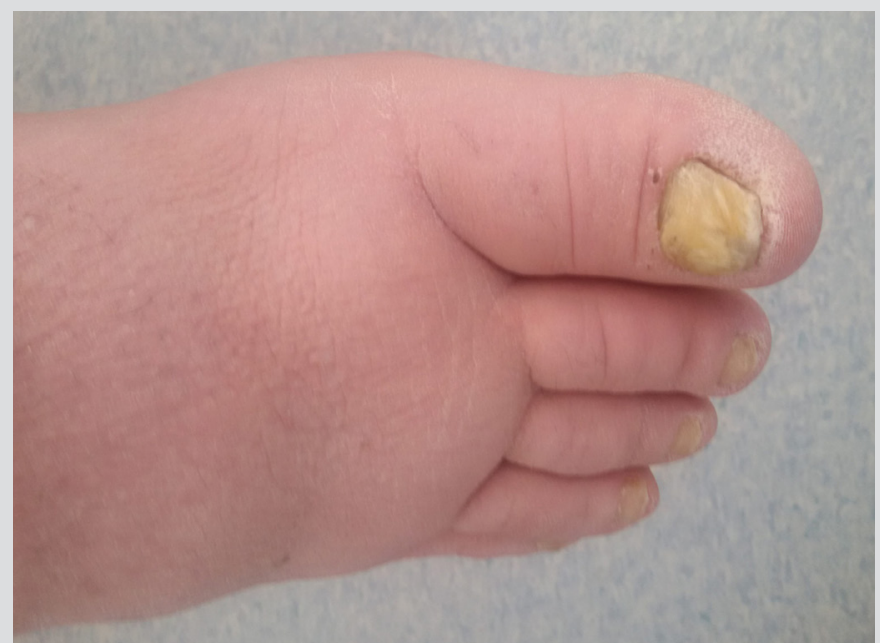

Figure 4: Lymphedema and dystrophic yellowish nails

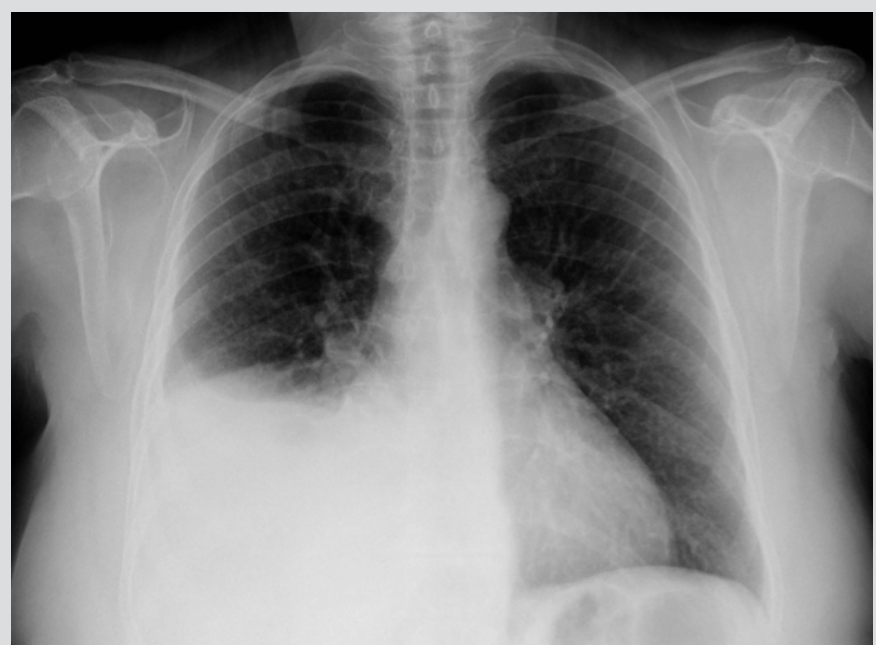

Figure 5: Pleural effusion in the lower half of the right hemithorax 


\begin{tabular}{|c|c|c|}
\hline Haematology/Biochemistry/Imunology & Reference range & Case Report 2 \\
\hline Haemoglobin (g/dl) & $12.0-15.0$ & 14.9 \\
\hline White blood cells (/mm3) & $4.000-10.000$ & 4600 \\
\hline Neutrophils (\%) & $40-80$ & 69.1 \\
\hline Platelet count (/mm3) & $150.000-400.000$ & 246.000 \\
\hline C-reactive protein (mg/dl) & $<0.5$ & 0.8 \\
\hline Erythrocyte sedimentation rate $(\mathrm{mm} / \mathrm{h})$ & $<20$ & 19 \\
\hline Troponin I (ug/l) & $<0.04$ & 0.02 \\
\hline Creatinine (mg/dl) & $0.52-1.04$ & 0.78 \\
\hline Urea (mg/dl) & $15-36$ & 49 \\
\hline Total proteins (g/dl) & 6.2-8.6 & 7.5 \\
\hline Albumin (g/dl) & $3.5-5.0$ & 4.3 \\
\hline Protein electrophoresis & & Normal \\
\hline BNP threshold (pg/ml) & $<125$ & 136 \\
\hline Sodium (mmol/l) & $136-145$ & 145 \\
\hline Potassium (mmol/l) & $3.50-5.10$ & 3.86 \\
\hline Aspartate aminotransferase (U/L) & $14-36$ & 24 \\
\hline Alanine aminotransferase (U/L) & $10-52$ & 30 \\
\hline Alkaline phosphatase (U/L) & $25-100$ & 111 \\
\hline Lactate dehydrogenase (U/L) & $313-618$ & 487 \\
\hline $\mathrm{TSH}(\mu \mathrm{U} / \mathrm{ml})$ & $0.46-4.68$ & 0.93 \\
\hline Free T4 (pmol/l) & $10.9-28.2$ & 19.8 \\
\hline Antinuclear antibodies & negative & negative \\
\hline Rheumatoid factor (UI/ml) & $<15$ & $<11.1$ \\
\hline Antineutrophil cytoplasmic antibodies & negative & negative \\
\hline C3 complement/ C4 complement (mg/dl) & $90-180 / 10-40$ & $129 / 35.9$ \\
\hline Hepatitis B surface antigen (HBsAg) & negative & negative \\
\hline Anti-hepatitis C virus (anti-HVC) & negative & negative \\
\hline Anti-HIV 1 and 2 antibodies & negative & negative \\
\hline \multicolumn{3}{|l|}{ Urine } \\
\hline Erytrocyte & negative & negative \\
\hline Leukocyte & negative & negative \\
\hline Protein & negative & negative \\
\hline
\end{tabular}

Table 2: Patient's laboratory tests

*inclues anti-Ro antibodies, anti-La antibodies, anti-SM antibodies, anti-nRNP antibodies, anti-Scl-70 antibodies, anti-Jo1 antibodies;

** perinuclear and cytoplasmic

\section{CASE REPORT 2}

A 58-year-old woman, a heavy smoker, was admitted to the emergency room complaining of increased dyspnoea and swelling of the lower limbs for 5 days. The patient had a clinical history of total thyroidectomy (Grave's disease), lymphedema, chronic cough and sinusitis. She noticed since the age of 50 recurrent respiratory tract infections and thick, yellow nails. Physical examination revealed an obese patient with $90 \%$ oximetry in room air; muffled heart sounds and vesicular murmur diminished on the lower half of the right hemithorax; 
severe lymphedema of both legs and dystrophic yellowish nails (Fig. 4), with remaining examination without changes. Chest radiograph demonstrated a moderate right pleural effusion and an increased cardiothoracic index (Fig. 5) that the high-resolution CT scan confirmed. Transthoracic echocardiogram revealed a bulky pericardial effusion without haemodynamic instability and preserved ejection fraction. Laboratory tests are presented in Table 2. The thoracentesis revealed an exudative pleural fluid, with lymphocytic predominance that was negative for malignant cells. Exams of blood and pleural liquid cultures were negatives. Pleural biopsy was in favour of chronic fibrosis. The patient was prescribed a low-salt diet, a therapeutic diuretic, respiratory therapy and elastic bandage with improvement of the patient's clinical condition, including the pericardial effusion. However, since then, the patient has been hospitalized multiple times for recrudescence of pleural effusion. A diagnosis of YNS was made, as all etiological investigations performed were inconclusive.

\section{DISCUSSION}

The diagnosis of YNS is often delayed due to the rarity and non-specificity of the related respiratory symptoms ${ }^{2}$. Classic presentation (yellow nails, lymphedema and pleural effusion) is only present in $25 \%$ of cases ${ }^{4}$. When present, pleural effusion is in almost all cases an exudate, with a predominance of lymphocytic cells ${ }^{1,2}$. Despite yellow colouration, patients with YNS can have other nail changes such as slow growth, thickening, transverse ridging, excessive curvature, or onycholysis ${ }^{1}$. The lymphedema is typically non-pitting and usually involves symmetrically lower limbs, but has also been described in the face, upper limbs and peritoneal cavity ${ }^{1}$. Pericardial effusion related with YNS was first reported in 1987, and in the study by Maldonado et al, $20 \%$ of the patients that performed echocardiography had a mild-tomoderate pericardial effusion².

The pathogenesis of YNS is still obscure, however available studies suggest an important role of impaired lymphatic drainage and of a protein leakage ${ }^{1,2}$. Because of this, no specific treatment exists unless the present therapy provided to these patients is based on the relief of symptoms, except when a possible underlying pathology is known. In that case, patients must experience initial treatment for the base pathology when possible, and only after symptomatic treatment.

In our patients, we achieved reasonable symptomatic control with diuretics, a salt-free diet, and bronchopulmonary hygiene measures and, in the second case, recurrent thoracentesis (in YNS, pleural effusions tend to recur and can be managed by multiple thoracentesis and pleurodesis). With the control of respiratory symptoms, an improvement in nail changes and lymphedema are often observed ${ }^{1}$. Alternative therapies have recently been tried (such as vitamin E, octreotide, enteral azoles, topical and systemic corticosteroids) with some promising results, however further studies are needed ${ }^{2,3,5}$.

The long-term outcome for patients with YNS appears favourable, with life expectancy slightly shorter when compared to healthy patients ${ }^{1,2}$, largely dependent on the severity of respiratory manifestations and the underlying clinical condition. The authors suspected that YNS in the first case report is probably in association with breast cancer, while in the second case the base condition remains unclear. The authors hope to draw attention to this likely under-diagnosed condition and whose diagnosis should be led by investigations for related conditions.

\section{REFERENCES}

1. Maldonado F, Ryu J. Yellow nail syndrome. Curr Opin Pulm Med 2009;15: 371-375.

2. Maldonado F, Tazelaar H.D, Wang C, Ruy J. Yellow Nail Syndrome, analysis of 41 consecutive patients. Chest 2008;134:375-381.

3. Lotfollahi L, Abedini A, Darazam IA, Kiani A, Fadaii A. Yellow Nail Syndrome: Report of a Case Successfully Treated with Octreotide. Tanaffos 2015;14:67-71.

4. Nanda S, Dorviller F. Yellow nail syndrome: clinical images. CMAJ 2009; 181:614 doi:10.1503/cmaj.080255.

5. Banerjee A, Kanti-Biswas A, Bala S, Ghosh A. Yellow nail syndrome: A rare entity. Indian Dermatol Online J 2014;5:529-31. 